\title{
Human-Animal Relationships and Social Work: Opportunities Beyond the Veterinary Environment
}

\author{
Phil Arkow ${ }^{1}$ \\ Published online: 5 September 2020 \\ (c) Springer Science+Business Media, LLC, part of Springer Nature 2020
}

\begin{abstract}
A species-spanning approach that incorporates clients' relationships with their companion animals into family genograms, schools of social work curricula, continuing education, interviews, assessments, and interventions offers increased career opportunities, professional and personal growth and development, and a more comprehensive resolution of clients' issues, social justice concerns, and the prevention of family violence. This article identifies six reasons why social workers should be cognizant of human-animal relationships and introduces nine ways, with action steps, in which social workers can include these relationships into training and practice outside the more developed field of veterinary social work. These venues include: agencies working in child protection and child sexual abuse; children's advocacy centers and courthouse facility dogs; animal shelters; domestic violence shelters; public policy advocacy; clinical practice; agencies working with older and disabled populations; veterinary sentinels for intimate partner violence; and pet support services for homeless populations. Such attention to the human-animal bond can utilize social workers' problem-solving skills to improve delivery of services, identify clients' risk and resiliency factors, enhance social and environmental justice, expand academic inquiry, and increase attention to all of the vulnerable members of families and communities.
\end{abstract}

Keywords Animal $\cdot$ Child abuse $\cdot$ Veterinary medicine $\cdot$ Domestic violence $\cdot$ Social capital

\section{The Significance of Human-Animal Relationships for Social Workers}

While social work has long focused exclusively on the human members of society, companion animals are widely present in a majority of U.S. households and can represent highly significant emotional attachments and logistical challenges for their owners. More homes in the U.S. are said to have companion animals than have children (Vincent, McDonald, Poe, \& Deisner, 2019). 99\% of dog owners and $96 \%$ of cat owners view pets as either members of the family or close companions (American Veterinary Medical Association, 2018). There is widespread evidence of the potential health and well-being benefits of human-animal interactions across the life cycle in slowing the development and progression of chronic illnesses by decreasing loneliness and depression, decreasing anxiety and sympathetic nervous

Phil Arkow

arkowpets@snip.net

1 The National Link Coalition, 16 Grasshopper Drive, Etowah, NC 28729, USA system arousal, and improving physical fitness by providing an impetus to exercise (Friedmann, 2019). There is, conversely, substantial evidence of animal abuse as a potential precursor and indicator of interpersonal violence often linked to child maltreatment, intimate partner violence and elder abuse (Arkow, 2015a).

Pets occupy central roles in many interpersonal and intrafamilial relationships (Turner, 2006). They may serve as significant others, confidants, attachment figures, and sources of companionship (McNicholas \& Collis, 2006). They can be vital members of an individual's support system and facilitators to foster social capital, trust, civic participation and a sense of safety and community (Wood, Martin, Christian, Houghton, \& Kawachi, 2017). The relationships between humans and animals in a household may mirror the status of the health and safety of the people in that family (Hoffer, Hargreaves-Cormany, Muirhead \& Meloy, 2018).

Inquiring about children's and adolescents' experiences with animals can help social workers address risk and resilience factors. Pets' physical condition and behaviors can provide clues to human experiences and family functioning. Human-animal relationships are contextual for learning 
and resilience in the wake of family violence. Strengthening these relationships, and helping people better understand their animals' behaviors, can promote well-being in both species and enable people to leverage inclusion and a sense of belonging in community relationships. Animal rights arguments about inherent "speciesism" in humans' relationships with other animals should resonate well with social work's commitment to social justice and fighting oppression (National Link Coalition, 2019a).

This article explores six reasons why human-animal relationships can be significant to social workers' responsiveness to their clients and nine areas outside the veterinary social work environment where an understanding of clients' interactions with animals can be directed into enhanced professional and personal growth, innovative species-spanning solutions, and potential career opportunities.

\section{A Twenty-First Century Definition of "Family" Includes its Non-human Members As Well}

The American Veterinary Medical Association (2018) estimated that $57 \%$ of U.S. households owned a pet, including 76.8 million dogs, 58.3 million cats, plus birds, horses and other companion animals. Pets are predominantly found in households self-defined as "family" rather than "non-family" and the highest rates of dog and cat ownership continue to be among households with children. Primary responsibility for pets' care continues to rest overwhelmingly with the female members of the household. Pet ownership rates are higher in rural areas and lower in densely urbanized cities. There are unexplained racial and ethnic disparities in the rates of pet ownership; pets are found in $64.7 \%$ of white households, compared with Latino/Hispanic (61.4\%), Asian (46.6\%), and Black/African American (36.9\%).

Some pet owners describe veterinarians as "the other family doctor" (National Link Coalition, 2019b). Two studies reported that $87 \%$ (Risley-Curtiss et al. 2006a; RisleyCurtiss, Holley, \& Wolf, b) and 97\% (Risley-Curtiss et al., 2006a, b) of multi-ethnic pet owners agreed that their pets are members of the family.

In short, social workers exploring a client's home life and family dynamics may be missing a significant piece of the puzzle if they neglect to inquire about the client's animals and the attachments, relationships, and problems with them.

\section{The Presence of Pets Enhances Communities' Social Capital}

In addition to appreciating a client's individual and familial attachments or antipathy toward pets, social workers can achieve a fuller understanding of a client's connectivity or isolation from the community by seeing human-animal relationships in a social context.
Social capital (as contrasted with human capital, economic capital, cultural capital, technological capital, or other community resources) is the connectivity among people which enhances cooperation for mutual benefit. The concept was popularized by Putnam (2000) describing the networks and other forces that build social cohesion, personal investment, reciprocity, civic engagement, and interpersonal trust among community residents.

Notably absent, however, from the work of Putnam and other social capital researchers was inclusion of the influence of pets in a community (Arkow, 2013). This knowledge gap was addressed by Wood et al. in studies in Australia (Wood, Giles-Corti, \& Bulsara, 2005; Wood, Giles-Corti, Bulsara, \& Bosch, 2007,2009) and the U.S. (2017) which reported companion animal ownership to be positively associated with social capital, civic engagement, perceptions of neighborhood friendliness, and a sense of community. The ability of pets to generate interpersonal communications was greater than minor conversational exchanges among dog-walkers: the visible presence of people walking dogs and the impetus dogs provide for people to be outdoors and use park areas ameliorated negative mental health conditions and gave residents a feeling of greater collective safety and sense of community. Companion animal owners were found to be more likely to participate in volunteer, school and sports activities, professional associations and environmental campaigns. They were reported to be more likely to vote and to exchange favors with neighbors.

Arkow (2019a, 2013) proposed a converse, that the absence of companion animals in communities where rates of pet ownership are lower and incidence of animal problems is greater might contribute to less social connectivity and cohesion. Levinthal (2010) used geospatial mapping techniques to correlate the distribution and prevalence of animal neglect, abuse and dog fighting in Philadelphia with domestic violence and child maltreatment. She reported a highcrime neighborhood seemed to predict animal abuse, and that animal neglect correlated with demographic, cultural, and structural aspects of block groups, suggesting social disorganization may lead to animal neglect. Campbell (2019) used geospatial mapping techniques to report direct correlations between animal control complaints and domestic violence incidents in neighborhoods in Indianapolis.

Bruni (2019) suggested a way to push back on "the degradation of our country's civil culture" can be found in walking one's dog in public spaces. Dog walks encourage "honest-to-goodness conversations with actual strangers" that leave their owners "feeling a little less isolated, a little less disconnected" and discourage Americans retreating into "increasingly homogeneous enclaves." Dog-walking encourages mutual courtesy and reciprocal generosity. "When you're about to bend down and scoop up your beloved's 
odoriferous bequest, there's no snobbery and no timidity, only solidarity," he wrote.

\section{Asking About Pets Can Build Rapport and Trust}

There is something immensely powerful about animals that attracts and motivates humans, a force that is especially compelling with youths. Whether discussing pet ownership, fascination with wild animals, or imaginary animals, children are particularly engaged, and asking about animalrelated experiences can provide important information and establish a caring persona and a trusting relationship (Melson \& Fine, 2015; Boat, 2010).

A pet is a communication waiting to happen. A recurring theme in the literature is that companion animals are what Messent (1983, p. 37) first called "social lubricants," icebreakers who facilitate social support and interpersonal communications (Garrity \& Stallones, 1998). The nonjudgmental nature and unconditional positive regard of human-animal interactions can be a useful bridge for establishing rapport between therapists and clients (Arkow, 2015b). Because animals slip under the radar of human defense mechanisms, clients who are fearful, traumatized or under stress may be more willing to talk about their concerns for their animals before opening up and describing their own vulnerabilities (Melson \& Fine, 2015). Fawcett and Gullone (2001) reported that even the mere observation of animals can result in reduced physiological responses to stressors and increased positive mood. Lange, Cox, Benert, \& Jenkins (2006) reported animals can introduce a calming effect, stress-reducing humor, increased feelings of safety, experienced empathy, and motivation among adolescents attending anger management sessions.

Chandler (2005) wrote that discussing pets can easily segue into a discussion about the client's family support system and how well he or she is utilizing personal resources. An interaction with a therapy animal can enhance social workers' listening responses, convey empathy and help the client access feelings. She observed that it is not the mere presence of an animal, but rather the orchestrated child-dog and child-therapist interactions, that can facilitate client motivation and participation, enhance the relationship with the client, stimulate client focus and attention to task, and reinforce positive client change.

\section{Children's Positive and Negative Experiences with Animals Can Have Lifelong Implications}

Margaret Mead's oft-quoted adage (1964) that "One of the most dangerous things that can happen to a child is to kill or torture an animal and get away with it" has been substantiated with research. A growing body of evidence suggests that bonds formed or broken with companion animals in childhood reverberate and resonate across the lifespan (Jalongo, 2004). Childhood acts of committing or witnessing animal cruelty: may be sentinel warnings that a child is living in a dysfunctional environment and may be exhibiting other antisocial behaviors (Gullone, 2012); are a prime risk factor for perpetrating animal cruelty, bullying behaviors and violence against humans; and may lead to desensitization, decreased empathy, learned maladaptive coping mechanisms, and unresolved feelings of anger, fear and resentment, particularly if the child is also experiencing co-occurring family violence (Ladny \& Meyer, 2019). Correlations between childhood exposure to animal abuse and bullying behaviors have been reported by several authors (for example, see Baldry, 2005; Gullone \& Robertson, 2008; Henry \& Sanders, 2007; Parkes \& Signal, 2017; Sanders \& Henry, 2015; Vaughn et al., 2011; Walters, 2019). Currie (2006) reported that children exposed to domestic violence were three times more likely to have been cruel to animals than children not exposed to intimate partner violence (IPV).

\section{Animal Abuse Can Reveal Other Forms of Family Violence}

There is increasing academic and programmatic recognition of animal abuse and neglect as sentinel indicators of concurrent or future family violence, particularly child maltreatment and child sexual abuse, IPV and elder abuse. Social workers may find that when animals are abused people are at risk, and when people are abused animals may be at risk (Arkow, 2019b).

Emotional attachments to companion animals are often exploited by abusers in violence-prone households to control and coerce victims in domestic violence, sexual assault, child abuse, and elder abuse situations (Ascione \& Arkow, 1999) and fear of leaving a pet behind is a significant barrier that keeps women and children from extricating themselves from abusive situations (Roguski, 2012; Ascione, 2007). Households marked by IPV have higher-than-average rates of pet ownership and are extreme high-risk environments when animal abuse is also present: nearly $80 \%$ of IPV survivors where suspects also had histories of animal abuse feared they would be killed, $76 \%$ had been strangled and $26 \%$ had been forced into non-consensual sex. Multidisciplinary collaborations were seen as critical in prevention, detection and intervention to address substantial risk of harm for all children, adults and animals residing in the home (Campbell, Hicks, Thompson, \& Wiehe, 2017).

\section{Pet Loss Can Have Significant Implications}

Grief over the loss of a pet is a broad, complex construct, which can be complicated by pet owners' perceptions that they have minimal social support sources and negative 
veterinary interactions (Rémillard, Meehan, Kelton, \& Coe, 2017). The loss of a pet through death or disappearance, and the decisions inherent in determining whether euthanasia of a beloved animal companion is necessary and appropriate, can generate significant emotional trauma for human members of families as well as staffs of veterinary facilities and animal shelters (see, e.g., Barnard-Nguyen, Breit, Anderson, \& Nielsen, 2016; Carmack, 2003; Dunn, Mehler, \& Greenberg, 2005; Laing \& Maylea, 2018; Miller, Prout, Rourke, Lefkowitz, \& Boyer, 2014; Ross, 2005). Social workers who have had training in grief and loss theory are well positioned to be resources for individuals experiencing these emotions and can aid them in making difficult decisions and navigating the options available.

Because pets generally have shorter lifespans than humans, families are likely to witness significant life-cycle events such as birth, serious illness and death of their animal companions, who are often seen by children as peers and family members. The inevitable death of a pet can bring a profound sense of loss, with patterns of bereavement similar to those experienced with the death of a human family member or friend, and thus an opportunity for social work intervention.

Several studies have reported that by adolescence the majority of children have experienced pet loss through death or disappearance (Melson \& Fine, 2015). Social workers can play important roles in offering grieving clients opportunities for validation of their feelings, memorialization of the animal, resolution of potential feelings of guilt, and closure.

\section{Incorporating These Dynamics into Career Opportunities Beyond the Veterinary Social Work Environment}

Social work's interest in human-animal relationships has its origins in the practitioner-client-patient dynamics of the veterinary hospital or clinic. From modest beginnings at the Veterinary Hospital of the University of Pennsylvania in 1978 (Quackenbush, 1981; Quackenbush \& Glickman, 1983), the field of veterinary social work has grown dramatically in recent years. The term veterinary social work is believed to have been coined in 2002 by Elizabeth Strand, founding director of the Veterinary Social Work Certificate Program at the University of Tennessee-Knoxville. Today, dozens of students have been trained in the four areas of veterinary social work: the link between human and animal violence; grief and loss; animal-assisted interactions; and compassion fatigue management. This work may include:

- Supportive grief support and counseling with end-of-life decisions and follow-up.

- Advocacy and brokering of resources.
- Circulating reading materials and educational packets.

- Crisis intervention.

- Assessment of suicidal tendencies, mental health issues and domestic violence issues.

- Facilitation of a pet loss support group for hospital clientele and the community.

- Staff debriefing sessions.

- Client consultations and follow-up.

- Presentations to staff.

- Referral of mental health services for staff.

- Recommendations to administrators.

- Making improvements to client comfort on-site. (Larkin, 2016)

As the field of Veterinary Social Work gains additional recognition both within and outside the world of social work, additional opportunities will continue to emerge whereby an understanding of human-animal relationships becomes a valuable asset in many aspects of social work practice. This process can begin with something as simple as routinely including pets in family genograms and adding relevant coursework in schools of social work and continuing education as well as field placement opportunities. By demonstrating additional opportunities for social workers to include human-animal relationships in interventions and assessments and to be aware of community resources that can resolve clients' animal-related concerns, social workers can be more holistic and effective in resolving clients' needs and challenges and preventing further abuse of vulnerable members of families and communities.

Social work's legacy of facilitating collaborative community change can open up many new career opportunities by incorporating human-animal relationships into social work practice. Inquiring about the presence (or absence), stability (or turbulence), attachments, dangerousness, history, and status of animals within clients' lives can help social workers to obtain more comprehensive family assessments, validate important intra-familial relationships, build stronger support networks, support resiliency, gain earlier recognition of abusive behaviors, and address clients' animal care concerns with practical, appropriate and affordable solutions. These emerging opportunities include:

\section{Child Protection and Child Sexual Abuse Agencies}

Despite the social reformer origins of child protective services established by humane societies and SPCAs in the latter third of the 19th Century (Hoy-Gerlach, Delgado, Sloane, \& Arkow, 2019), there is a peculiar and unfortunate irony in that child and animal welfare agencies today operate wholly independently with little to no trans-species cross-fertilization of ideas, information or collaboration (Arkow, 2010; Walker, 1980; Zilney \& Zilney, 2005). This inter-agency 
communications gap can have tragic consequences, as with a case in Brooklyn, N.Y. in which a child whose family was under investigation by child protective services was killed by a dangerous dog in the home (Baker \& Stelloh, 2011). The author has heard anecdotally of three children under the aegis of child protection agencies in Oxford, Fla., and St. John, N.B., Canada, who were killed by pet snakes.

The potential impact of animals in the lives of children cannot be overstated and warrants expanding the ecological lens of child welfare work to include animals (Risley-Curtiss, 2013). Companion animals are found in $67.7 \%$ of households with children under age 6 and $74.6 \%$ of households with children over age 6 (AVMA, 2007). Melson (2001) reported that pets are more likely to be a part of children's growing up than are siblings or fathers, and that animals are pervasive in children's media, stories, imagination, and play. She reported that words for different animals-dog, cat, duck, horse, bear, bird and cow-are among the first 50 words that toddlers learn; children include $d o g$ and cat in their initial productive vocabularies more than any other words except mama and daddy. An estimated 80 to $90 \%$ of children first confront the loss of a loved one when a pet dies, disappears, or is abandoned (Melson \& Fine, 2015).

Melson (2013) reported that children, from an early age, view animals as living actors who have autonomy, intentionality and feeling. Children are often animals' caregivers; since opportunities for and encouragement of nurturing others are rare in childhood, nurturing animals makes up a large proportion of childhood caregiving experiences. Because caring for pets is gender-neutral, companion animals may develop innate nurturing skills in boys and feelings of mastery and self-efficacy among children who feel dependent and powerless.

Many children turn to their pets for reassurance and emotional support during times of stress. Companion animals may assist children in feeling security and unconditional love and contribute to a child's cognitive and language development (Risley-Curtiss, 2013). Companion animals may be sentinels of unsafe environmental conditions, mirroring family tensions and serving as cues in assessments that explore family issues. As one of the sub-systems within a complex family system, the inclusion of questions and observations about the current and past presence of animals in a child's environment, the meaning those animals have for each family member, their care, and whether any of them have been killed or hurt can be important to effective family-centered practice (Risley-Curtiss, 2013).

Children may feel safer talking about their pets' experiences before they disclose their own, thereby opening a friendly channel where children can provide important information (Melson \& Fine, 2006; Boat, 2010). Introducing therapy animals into the interview process can further advance this process, easing the stresses of such sessions, establishing rapport, providing the child with a sense of comfort, and creating a less threatening environment (Menzies, 2003), particularly in working with sexuallyabused children (Reichert, 1998).

Of particular concern is the nexus of animal sexual abuse or bestiality with child sexual abuse. Edwards (2019) reported $31.6 \%$ of animal sex offenders also had histories of sexually offending children or adults and $10.8 \%$ had prior convictions for child pornography. Her survey of 456 offenders arrested for bestiality between 1975 and 2015 found at least 213 children and 28 adults had been directly sexually victimized by the offenders, and that in 25 arrests (5.5\%) animal pornography had been used to groom a child for sexual behavior. The Canadian Centre for Child Protection (2018) reported significant overlaps of animal and human sexual abuse in a study of 38 cases of bestiality. In $82 \%$ of cases, sexual abuse of children occurred as frequently as, if not more frequently, than coerced sexual abuse of an animal. In $68 \%$ of cases involving both child and animal sexual abuse, the offender was in a position of trust over the child, usually a close family member.

Child welfare workers can obtain more accurate and useful assessments of child safety and well-being by taking several steps:

- In conducting child welfare checks and ongoing case management, look for: potentially abused, neglected or dangerous animals (e.g., aggressive dogs, poisonous reptiles, exotic species, dog- and cock-fighting paraphernalia); animals needing veterinary care; excess numbers of animals; and inadequate food, water or shelter. Animal health issues such as fleas or other parasites could have a direct impact on the health of the humans in the home. Include these findings in evaluations of the child's living environment, lifestyle and risk factors as potential threats to the child's well-being. Such conditions may also be illegal under a jurisdiction's laws.

- Consider a turbulent history of frequent turnover of animals as potential indicators of a family's inability to make strong, lasting emotional attachments.

- Include the child's emotional attachment to pets as a key support which may help build resiliency and a protective factor that mitigates. Treat the death or disappearance of animals as potentially as emotionally charged as the death of a human family member.

- Identify whether the child has been traumatized by witnessing or causing the abuse or death of animals.

- Consider animal maltreatment as a factor that supports a finding of child abuse or neglect. 
- Report suspected animal maltreatment to the animal control/services, humane society/SPCA, or law enforcement agency in that jurisdiction. ${ }^{1}$ The reporter need not prove that animal abuse occurred, but rather introduces the case into those agencies' investigative systems to vet the information and follow through as appropriate. Confidentiality restrictions may be waived in reporting to another such law enforcement agency, or when the welfare of the client and others in the household is threatened. Establishing channels of communication with animal welfare agencies in advance can simplify the cross-reporting process when a case of suspected abuse occurs.

- A history of animal cruelty, and a child's emotional attachments to animals, may have evidentiary importance in court trials, dispositions and hearings involving child maltreatment, custody, visitation, removal, and protection orders.

By asking three simple open-ended questions, social workers can learn much about a child's experiences with the animals and humans who share his or her environment:

- Are there animals at home?

- How are they cared for?

- Are you worried about their welfare?

Follow-up questions about their names, breeds, play activities, deaths or disappearances, recent health problems or injuries, and secrets the child shares with them may fill in details of the family dynamics, patterns of power and control, and risk and resiliency factors in the child's life.

\section{Children's Advocacy Centers and Courthouse Facility Dogs}

Facility animals in children's advocacy centers, CASA (Court Appointed Special Advocates), guardians ad litem programs, and courtrooms provide emotional support to sexual abuse survivors as they undergo forensic examinations, re-live their experiences, and confront their abusers (LaBahn, 2015). As of May, 2020, an estimated 238 dogs are working in courtrooms and children's advocacy centers in 40 states, plus others in Canada, Australia, Chile, and Europe (Courthouse Dogs Foundation, 2020a, 2020b, 2020c).

\footnotetext{
${ }^{1}$ Unlike coordinated state-run child protection systems, animal protection is handled exclusively on the local level by a fragmented patchwork of independent government animal control/services agencies, municipal/county law enforcement, and nonprofit humane societies/SPCAs. A national directory of animal abuse investigation agencies in over 6,500 jurisdictions is available at https://nationallinkcoa lition.org/how-do-i-report-suspected-abuse.
}

Elaborate precautions prevent handlers from violating client confidentiality and keep the dog's presence from adversely eliciting sympathy from a jury. Judges must balance the accommodation for a vulnerable witness with the potential for prejudice which could impact the defendant's right to a fair trial. Extensive guidelines on best practices protect the interests of the animal, the victim, the defendant, and the criminal justice system (Courthouse Dogs Foundation, 2015).

Social workers in victim services can be trained to be facility animal handlers or secondary dog handlers to allow the children to spend more time with the dogs after concluding their testimony. They can facilitate interactions between the dogs and distraught family members and stressed facility staff and be resources who connect individuals and institutions with facility animals in their community.

\section{Animal Shelters}

Nonprofit animal welfare and governmental animal control agencies have historically operated in isolation outside the purview of human services agencies, leading to a "silo" effect in which cross-disciplinary and trans-species collaborations rarely occur (Becker \& French, 2004) due to increased specialization, avoidance of "mission creep" and fear of violating confidentialities. Consequently, interagency cooperation and cross-training is minimal, resulting in a significant barrier to change. Meanwhile, animal shelter workers experience significant stressors including animal suffering and euthanasia, responsibility for life, abusive clients, negative public perceptions, and attachments to animals under their care (Schneider \& Roberts, 2016) without recognizing that their counterparts in human services often experience similar stressors. This lack of knowledge and coordination among community systems constricts the potential for creative and effective collaborations and can increase the risk of harm to people and animals in situations where both human and animal abuse co-occur.

Social workers can facilitate bridging these segregated service delivery systems through the profession's longstanding commitment to community-level action, intervention and change. Social workers can work with animal shelters to organize species-spanning community coalitions, link organizational champions, and connect consumers and professionals for the well-being of underserved and at-risk individuals and family members (Long \& Kulkarni, 2013).

Social workers can help animal shelters build capacity by coordinating inter-disciplinary interaction and communication, gathering data, conducting research, and building resources. Increasing cross-systems knowledge and promoting individual and institutional relationships across systems, particularly vis-à-vis cross-reporting animal, child and elder abuse, can protect vulnerable 
populations and develop stronger community services (Long \& Kulkarni, 2013). Numerous animal shelters, often working with juvenile and adult detention centers, have implemented animal-assisted therapy interventions where individuals who have offended, or who are at risk, train dogs with behavior problems who are at risk of being euthanized. Using positive reinforcement techniques, these programs teach teamwork, non-violent conflict resolution and collaboration skills to save animals' lives and modify the behaviors of abusive and traumatized individuals (Arkow, 2019b).

Animal shelters appear poised for such systemic change. The service philosophy in the animal shelter community is evolving to recognize that treating the symptoms of animal welfare problems, such as animal homelessness, abuse and neglect, is only a stopgap solution: to be truly effective, underlying community and family dysfunction and violence must be addressed (PetLynx, 2011).

Hoy-Gerlach et al. (2019) described promising opportunities for social work field placements in community animal shelters, including: reducing staff and volunteers' compassion fatigue in an exceedingly difficult and emotionally draining work environment; placement of shelter pets as Emotional Support Animals; strengthening community responsiveness to violence through assessing overlaps and differences between child, elder and animal abuse investigations; creating and implementing educational programming across child and animal protection systems; and increasing community awareness of the link between violence to animals and violence to humans.

Animal control and humane officers frequently have access to pet owners' homes in the course of their investigations, and in the process may observe conditions detrimental to the welfare of children, youth and others. In addition, cruelty investigations which result in the removal of animals from a home could be an additional stressor on the family system and could lead to increased risk for vulnerable family members. Social workers can train shelter personnel on the intersectionality of animal abuse and human violence and the procedures for making referrals to social services agencies.

Other untapped social work opportunities in animal shelters might include: strengthening collaborations with domestic violence shelters and mobile meals programs; directing and expanding pet visitation programs for long-term care facilities and animal-assisted interventions for at-risk populations; developing pet loss grief support groups; developing safety net supportive programming for individuals who experience a medical, economic or housing crisis that temporarily makes it difficult to keep an animal; defusing contentious confrontations with shelter clients; resolving customers' complaints and needs for services; and connecting pet owners with community resources, such as low-cost pet and veterinary services, animal behavioral counselors, pet food banks, and social services agencies.

\section{Domestic Violence Shelters}

Social workers provide essential services to survivors of intimate partner violence and their children in numerous ways, including advocacy, practice and public policy. They serve as advocates in women's shelters, criminal courts, protective order offices, hospital ERs, police victim services units, government and nonprofit agencies, military family advocacy centers, fatality review teams, and elsewhere. Their work encompasses crisis intervention, investigations, counseling, case management, legal services, public policy, and referrals to and liaison with community resources. All of these aspects of social work practice can take on an additional dimension by incorporating human-animal relationships into the perspective. Research findings suggest that in working with pet-owning domestic violence victims, social workers must consider the welfare of the women's pets in order to effectively help the women achieve safety for themselves and their families (Strand \& Faver, 2005).

Domestic violence shelters in the 1990s began raising awareness that significant numbers of survivors (usually, but not always, women) and their children are either turned away from safehouses that will not accept their pets or are refusing to leave abusive situations for fear of what would happen to their pets if they left. These fears range from the mundane-that no one remaining at home would provide adequate care-to the tragedies of seeing animals tortured and killed in an emotional extortion that warns partners that they themselves could be the abuser's next victims.

The issue reached national awareness in 2006 when Susan Walsh, 50, told legislators in Maine that her husband had retaliated against her and her children and prevented her from leaving a frightening relationship by killing her pets and farm animals: "It wasn't just the cats and the dogs I had, it was the sheep and the chickens - I was terrified for their welfare. I knew if I were to leave, he wouldn't hesitate to kill them. He had done it before." (Belluck, 2006).

To address the problem, then-Gov. John Baldacci signed into law the first of what are now laws in 35 states plus Puerto Rico and the District of Columbia specifically allowing courts to include pets and, in some cases, livestock in domestic violence protection-from-abuse orders. These allow courts to grant petitioners exclusive care, custody and control of animals, and to forbid respondents from harming, taking or disposing of animals or even coming near them (National Link Coalition, 2019c).

Abusers' obsessive jealousy and control can become a manipulative tool for power over partners and children by exploiting the vulnerability their emotional attachment to pets. $71 \%$ of battered women reported that their abusers had 


\section{The "Power and Control Wheel" of Animal Abuse and Domestic Violence

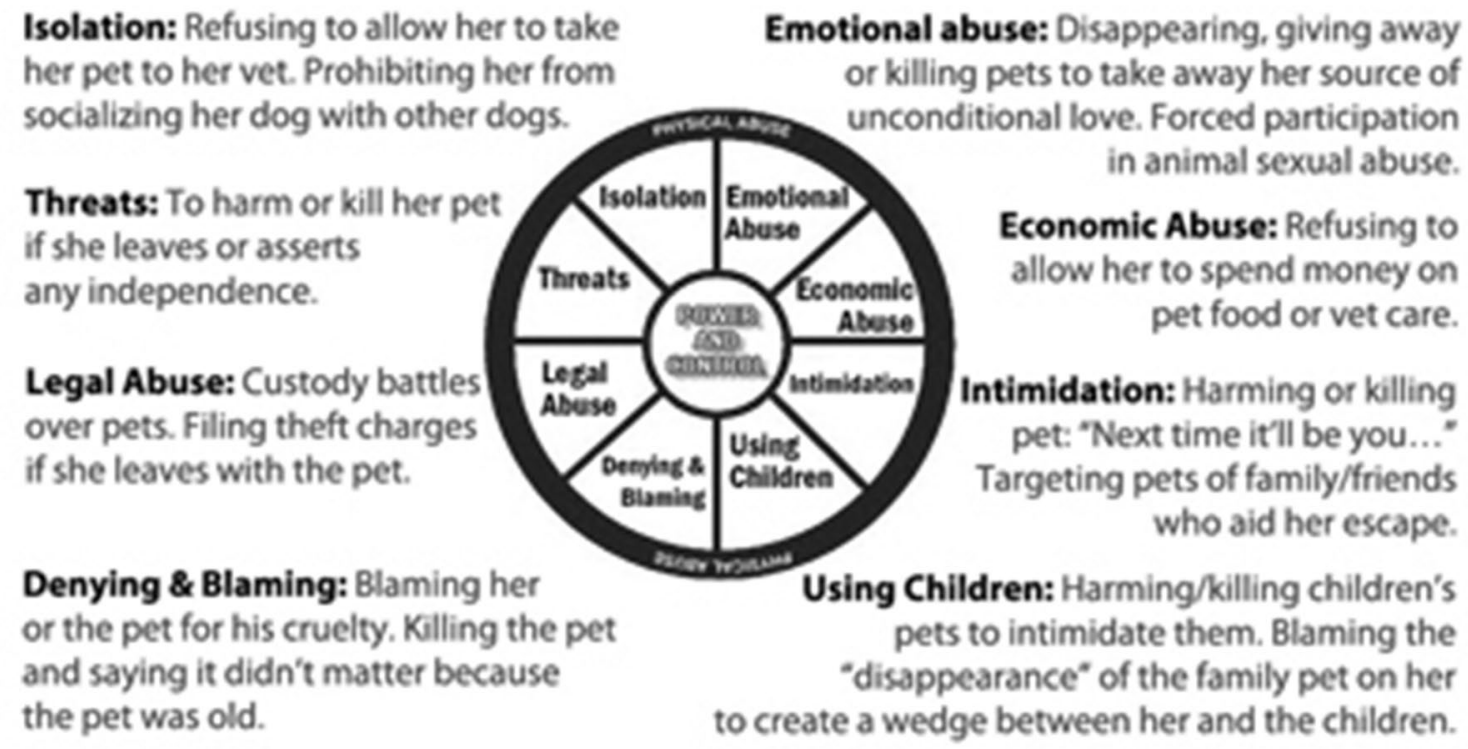

Fig. 1 Animal abuse within the context of domestic violence

harmed, killed or threatened animals as coercive control (Ascione, Weber \& Wood, 1997). 25\% to $40 \%$ of abused women delay seeking safety in fear for the welfare of their animals (McIntosh, 2002). 41\% of IPV offenders had histories of animal cruelty (Febres et al., 2014), which is one of the four strongest risk factors for becoming a batterer (Walton-Moss, Manganello, Frye, \& Campbell, 2005). Animals are chosen as soft targets because abusers believe that they can get away with it because police generally don't care about animal abuse (Roguski, 2012). When perpetrators of IPV also have a history of animal abuse, victims experience 20 to 50 violent incidents before contacting police and the risk of lethality to first responders doubles (Campbell, Thompson, Harris, \& Wiehe, 2018).

The risks encapsulated in these and similar findings are further escalated vis-à-vis the impact on children in these households: $87 \%$ of coercive IPV animal abuse incidents occurred in the presence of the woman; $75 \%$ occurred in the presence of the children (Quinlisk, 1999). 32\% of domestic violence survivors in shelters reported their children had also harmed animals, repeating the intergenerational cycle of violence (Ascione, 1998). Batterers have been reported to sexually abuse animals, threaten pets to get children to do something, or force the child to kill the pet (Jury, Thorburn, \& Burry, 2018).

The National Link Coalition (2017) modified the "Power and Control Wheel" frequently used to graphically depict the dimensions of domestic violence to demonstrate how animal abuse is incorporated in abusers' coercive control tactics, as shown in Fig. 1.

In response to these situations, domestic violence shelters are developing collaborative foster care programs with local animal welfare agencies to provide off-site "safe havens" for the animal survivors, thereby removing one barrier that prevents families from escaping abuse (Ascione, 2000). More recently, a program called SAF-TSheltering Animals and Families Together-is helping more than 200 domestic violence shelters in the U.S. and other countries build co-sheltering facilities for pets to keep all family members together and safe (Phillips, 2019). Grant funding is available to help shelters with capital costs and survivors with veterinary and boarding expenses (National Link Coalition, 2019d).

These concerns dictate bringing social workers into the planning process for innovative and collaborative intakes, assessments, responses, and referrals that incorporate human-animal relationships. Serious gaps often separate domestic violence and animal shelters: although concern for the safety of pets and livestock is a barrier to individuals leaving situations of IPV in urban and rural areas, one study reported that $76.92 \%$ of animal welfare representatives and $53.33 \%$ of human service representatives, respectively, reported no collaboration between their agencies (Saskatchewan SPCA \& STOPS, 2016). 
Social workers can facilitate the interests of IPV clients and their children and animals by:

- Gathering information about the status of animals and their (mis)treatment during crisis line calls, shelter intakes and risk assessments. As with child welfare agencies, interviewers can ask three open-ended questions which may build immediate rapport, reveal important family dynamics, and aid in evaluating clients' risk and protective factors: Are there animals at home? How are they cared for? Are you worried about their welfare?

- Coordinating with and making referrals to pet-related services for survivors, such as pet-friendly transitional housing, affordable veterinary care and pet boarding, and foster care with animal care and control agencies. Social workers can compile resource directories so domestic violence agencies know who to call for help with clients' animal issues.

- Helping clients to establish pet ownership by getting all of the animals' documentation in her name. This may include licenses, vaccination records, microchips, pedigree papers, and receipts from pet stores and veterinary clinics. Establishing such a record may mitigate protracted and contentious custody disputes in marriage dissolution proceedings; Alaska, California, Illinois, and New Hampshire have begun to address this issue by enacting laws whereby courts can award custody of pets in what the court determines to be the animals' best interests, modeling long-established practice in child custody.

- Including information about assaultive and coercive acts of animal cruelty in mental health assessments and rehabilitation of abusers and in the Specialized Domestic Violence Assessment of Risk to Children.

- Including relocation of pets in domestic violence agencies' safety plans (National Link Coalition, 2014).

- Obtaining information from local animal welfare and control agencies about prior investigations at the household.

- Inviting animal-assisted therapy teams into shelters to help comfort survivors.

- Counseling children regarding incidents of animal maltreatment, death or disappearance of pets that they may have witnessed or committed.

- Developing community education campaigns to alert the public and cross-train professionals about how animal abuse is linked with IPV. Veterinarians, in particular, whose staffs and clients are predominantly female, should begin to recognize a responsibility to serve as resources for survivors of IPV (Larkin, 2018; Newland, Boller, \& Boller, 2019).

\section{Public Policy Advocacy}

The well-established role of social workers as advocates for social justice provides additional opportunities to advance legislation that recognizes human-animal relationships, the beneficial aspects of pet ownership on individual and community health and well-being, and the adverse effects of animal abuse on human welfare and safety. As an underserved population, animals are classified as property and have long been ignored by the legal system; legislators frequently trivialize campaigns to protect their interests for the simple reasons that animals don't vote and human concerns are widely viewed as being more pressing.

However, recognition of the foundation that animal abuse is linked to human violence and therefore improving animal welfare improves human society is generating a new respect for animal welfare legislation. Current relevant public policy issues include legislation that would:

- Allow courts to include pets and/or livestock in protection-from-abuse orders (currently enacted in 35 states, Puerto Rico and the District of Columbia) (National Link Coalition, 2019c).

- Allow courts to award custody of pets in divorce and marriage dissolutions based upon the animals' best interests, similar to long-standing similar provisions affecting child custody (four states).

- Redefine animal abuse when committed as coercive control as also being an act of domestic or dating violence (11 states).

- Allow acts of violence against animals to be included in criteria for Extreme Risk Protection Orders that bar domestic violence abusers from obtaining firearms.

- Allow courts to appoint pro bono advocates to represent animals' interests in criminal cruelty cases, similar to established Court Appointed Special Advocates (CASA) provisions for children (three states).

- Mandate or permit child welfare, adult protection and animal services agencies to cross-report incidents of suspected animal, elder and child abuse to each other, and veterinarians to report suspected animal, child and elder abuse to appropriate agencies, with immunity from civil and criminal liability and professional disciplinary sanctions.

- Increase penalties for bestiality (now often considered animal sexual abuse) based upon increased evidence of its co-occurrence with child sexual abuse and child pornography. As of August, 2020, having sex with animals is still legal in Hawai' $i$, New Mexico, West Virginia, and Wyoming.

- Increase penalties for acts of animal cruelty when committed in the presence of a child or adolescent. 


\section{Clinical Social Work Practice}

Clinical social workers may become aware of clients' human-animal interactions through recognizing a client's attachments and issues vis-à-vis the animals in his or her environment and by introducing animals for therapeutic purposes to enhance the client-practitioner relationship.

In one of the earliest writings on the nexus of social work and human-animal interactions, Netting, Wilson, \& New (1987) outlined seven ways in which social workers can contribute to human-animal bonding:

- Being sensitive and supportive in counseling clients who have pet-related problems.

- Being aware of clients' relationships with their pets and assisting in locating support services that include pet care.

- Being aware of policies that affect pet ownership, such as restrictive housing conditions, and advocating for clients' pet-related interests.

- Assessing clients to determine their readiness to accept pet-related interventions.

- Being critical of how pet-related programs are developed and collaborating with animal professionals.

- Acknowledging potential benefits and problems which may accompany pet-related programs.

- Linking veterinarians into the human services referral network.

More recently, Silverman (2018) published a brief guide to ways in which social workers can utilize animals as a bridge between a therapist and patient in private practice. Animals can expedite rapport building with patients who have issues with attachment disorders and enhance the motivation to attend the session which improves retention and treatment outcomes. Animals may function as a surrogate of the therapist and allow for more ethical therapeutic touch, which could be a corrective experience for those with histories of trauma. Fostering the human-animal connection may help patients identify sustainable, long-term support to manage symptoms and maintain functioning after the therapeutic relationship with a clinical social worker has ended. She identified four categories of animals utilized in a helping capacity:

- Service animals, which are individually trained to do specific tasks for a person with a physical or sensory disability. Clinical social workers may recommend that a patient consider having a service animal and identify resources to obtain one.

- Emotional support animals, a newer and vaguer category, that provide emotional benefits to a person diag- nosed with a mental health disorder that impairs or limits functioning in one or more life domains.

- Comfort dogs, introduced in disaster responses to offer a calming presence to survivors and first responders.

- Animal-assisted therapy animals, professionally evaluated to be introduced in treatment plans with intentional, goal-directed activities to complement traditional interventions.

Social workers should note that spouses and partners may be jealous of a disabled individual's dependence upon and emotional attachment to a service animal. Also, the emotional support animal system has a potential for egregious abuses by individuals getting their animals so designated solely to accompany them on airplane flights; online services will provide such documentation from mental health professionals who have never examined the client.

\section{Social Work and Older and Disabled Populations}

Human-animal bonds may be particularly robust with older clients and present unique challenges. For individuals who are socially isolated, pets may be a significantly vital source of companionship and emotional support. Caring for a pet may be an especially strong motivator for a client to get out of bed, have a daily routine, nurture another being, or go for a walk. The animal may be a last link to a deceased spouse (Arkow, 2015a).

Human-animal social work issues relevant to older adults include:

- Animal Neglect: More than $92 \%$ of adult protective services respondents to a national survey reported animal neglect coexisting with a client's inability to care for himself/herself, indicating that reports of animal neglect may be an important warning sign for vulnerable adults' self-neglect (Lockwood, 2002). Animals may be neglected by frail elders who lack financial resources, transportation, or physical or mental capacity to care for them adequately (Peak, Ascione \& Doney, 2012).

- Self-neglect: Frail elders may neglect their own needs by spending limited financial resources on their animals' food and medications. Some may refuse to go into hospitals, assisted living or long-term healthcare facilities unless provisions are made for their pets (Boat \& Knight, 2000).

- Coercive control: In more than two-thirds of domestic/ elder abuse cases, the perpetrators were family members who may neglect or abuse the elder's pet as a form of control or retaliation, out of frustration over their caretaking responsibilities, or as a way to extract financial assets from the victim (Humane Society of the U.S., 2005). 
- Bereavement: Isolated seniors may experience profound grief and depression upon the death of a beloved pet. Some seniors are reluctant to replace departed pets in fear that the animals will outlive them (Boat \& Knight, 2000). Many older adults, particularly the widowed and elderly, are at risk of emotional trauma and experience significant disruptions in eating, sleeping, job-related responsibilities and other daily routines and decreased socialization behaviors following the death of a pet (Quackenbush, 1984).

- Denied services: Home health aides, social workers and other caregivers may be reluctant to enter seniors' dwellings if they fear the presence of aggressive animals or deteriorated environmental conditions linked with animal hoarding or neglect (Boat \& Knight, 2000).

- Animal hoarding: Animal hoarders may come from any cohort but they are statistically over-represented by older women (Patronek \& Nathanson, 2009). Animal hoarders (and their children) often live in unhealthy environments surrounded by dozens and even hundreds of living and deceased animals in states of neglect, starvation and suffering. Stereotypical hoarders, often labeled as "cat ladies," have been reported as living in a self-fulfilling cycle of social isolation: they gravitate towards animals because they are uncomfortable around people, and other people choose not to associate with them because of their excess number of animals. Many are experiencing mental health issues and a collaborative, multi-agency response is invariably required (Patronek, Loar, \& Nathanson, 2006). Nathanson (2009), in identifying four core barriers that limit adult protective services workers' involvement in these cases, called animal hoarding one of the most perplexing and problematic human-animal relationship and a deviant behavior associated with extremely deleterious conditions of comorbid animal and selfneglect. She identified training programs that can better prepare human services professionals to respond to these clients and engage in trans-species and interdisciplinary efforts essential for the safety, health and well-being of the hoarder, human and animal dependents, property, and community.

Social workers, whether in private practice, nonprofit organizations or governmental adult protective services agencies, can recognize the import of these human-animal relationships, locate support services for the animals and make appropriate referrals including temporary foster care and other pet services for owners who are in need of hospitalization, long-term care or other social services. Social work input on multidisciplinary teams can help to resolve the particularly challenging psychosocial aspects of animal hoarding. And social workers should be attuned to the potential that a client's requesting a veterinarian to have all of his or her pets euthanized is a potential sentinel warning sign for suicidal behavior. Social workers can help train veterinarians in recognizing this warning sign and responding with appropriate referrals.

\section{Veterinary Medicine and Domestic Violence}

An emerging frontier is exploring veterinary medicine's response to suspected domestic violence. An incident in DeLand, Fla. in 2018, when a woman being held captive at gunpoint by her abusive boyfriend was able to alert veterinary staff who in turn called the police (Robbins, 2018), brought to national attention what was just beginning to be discussed in professional journals: how should veterinarians and their staffs, the majority of whom now are women (Kelly, 2017), respond to suspected domestic violence in their clientele? (Newland et al., 2019; Larkin, 2018; Allison, Satterwhite, Ramaswamy, Hynek, \& Agnew-Svoboda, 2017).

Veterinarians in the United Kingdom and New Zealand have taken the most proactive responses in addressing this concern. Medics Against Violence, a Scottish collaborative of human and veterinary healthcare professionals, created a Domestic Abuse Veterinary Initiative to train veterinarians to help pet owners needing to escape domestic violence; the initiative was featured in a British Veterinary Association guidance for responses to suspected domestic abuse (Animal Welfare Federation and The Links Group, 2016). In 2015 , the Scottish government put $£ 115,000$ into a national campaign to train 100,000 front-line professionals in the three fields identified as most likely to encounter domestic violence survivors: dentists, veterinarians and hairdressers (Paterson, 2015). The U.K.'s Code of Professional Conduct for Veterinary Surgeons states, "Given the links between animal, child and domestic abuse, a veterinary surgeon or veterinary nurse reporting suspected or actual animal abuse should consider whether a child or adult within that home might also be at risk" (Royal College of Veterinary Surgeons, 2016).

The New Zealand Veterinary Association supported a national legislative response to family violence by describing veterinary medicine as a "three-dimensional profession" with a unique voice in issues that transcend animal life, human life and the environment. NZVA called for domestic violence protection-from-abuse orders to specifically include animals, and for changing the definition of domestic violence to include "coercive control" which would cover emotional and psychological abuse to family members through threat or harm to pets or farm animals (National Link Coalition, 2015). The Veterinary Council of New Zealand (2013), whose Code of Professional Conduct includes a recommendation that veterinarians confronted with situations of animal abuse should consider whether 
people within that home might also be at risk, published a guidance that included suggestions on preparing the practice and responding to domestic violence.

Social workers can help to introduce a response to intimate partner violence as a public health matter to a profession which has been reluctant to get involved, due to a lack of training and fears for personal safety, and help veterinary clinics develop protocols for response and dissemination of literature about community domestic violence resources to their clients. They can also coordinate programs linking students at colleges of veterinary medicine with local domestic violence shelters, such as has been done at Texas A \& M, Mississippi State University, and the University of Georgia.

\section{Pets and the Homeless}

Social workers can respond to the needs of pet owners who are homeless, whose attachments to their animal companions are often stronger compared with the general population (Labrecque \& Walsh, 2011). An estimated 5\% to $10 \%$ of the 3.5 million Americans who experience homelessness every year have dogs and cats, with rates as high as $25 \%$ in some areas. Because the vast majority of homeless shelters do not allow pets, these restrictions deter pet owners from seeking essential shelter (O'Reilly-Jones, 2019). Many individuals who live on the street keep pets, primarily dogs, for emotional support, safety, a sense of responsibility, to combat loneliness (Labrecque \& Walsh, 2011; Williams \& Hogg, 2016; Arnott, 2004), and as social catalysts to attract passers-by who may offer them money (Irvine, Kahl, \& Smith, 2012; Anderson, Snow, \& Cress, 1994).

Social workers can coordinate veterinary and foster care for the animals and advocate for pet-friendly co-shelters for the homeless much as has been done in domestic violence shelters (Phillips, 2019). Social workers can participate in such programs as the Street Dog Coalition, operating in 30 states, in which social work, veterinary and medical school students host clinics and provide resources to help the pets of homeless pet owners.

\section{Limitations}

An accurate representation of the roles of animals in families, and of social work's responsiveness to these dynamics, is compromised by several factors. Despite the above-cited market research data indicating a widespread population of companion animals and their over-representation among families with children, relatively little is known about the racial, ethnic, socioeconomic, age-related, or geographic demographics of pet-owning families, as such information has never been included in the U.S. Census (Arkow, 2019a).
Meanwhile, until recently, social workers have historically ignored the central role that companion animals may play in the lives of their clients, adopting an anthropocentric view underpinned by human rights and social justice (Laing \& Maylea, 2018). This is reflected in reports (National Link Coalition, 2020) that identified only 24 schools of social work in the U.S. and seven in Canada that are believed to include the topic of human-animal relationships in either undergraduate or graduate level study, or in the absence of such courses have a faculty member known to have a specialization in the human-animal bond. It is hoped that publications such as this will begin to address these shortcomings and increase awareness of human-animal relationships in the lives of social workers' clients.

\section{Conclusion}

The inclusion of human-animal relationships should be considered more widely in training and practice as part of social work's commitment to social and environmental justice and fighting oppression and seen as an expanding opportunity for research, practice, advocacy, and advancing public policy. In the process, additional career opportunities may open up with this species-spanning approach to resolving individual, family and community challenges.

Such inclusion can begin with something as simple as routinely including companion animals in genograms, ecomapping, and definitions of family support systems (Risley-Curtiss, 2010; Hodgson \& Darling, 2011). As assessing clients' needs is an important step in developing the best plan to solve clients' problems, including pet protective factors in clients' ecologies should be considered a relevant environmental factor in social work practice theory (Sato, 2011). Collecting information about all the pets and humans in a family communicates interest and concern for the whole family and demonstrates an integrated approach to care that can help in planning appropriate interventions and preventive care. Human-animal bond awareness can be further expanded by adding relevant coursework and field placements in schools of social work and training programs in continuing education.

Given the established links between animal cruelty and other forms of violence within the family system (Arkow, 2019b), questions about human-animal interactions and relationships and clients' committing and/or witnessing acts of animal abuse should be systemically, not just optionally, introduced in intakes and assessments.

Incorporating the significance of human-animal interactions can help modernize what has been an intrinsic anthropocentrism of social work's theoretical foundations. Growing opportunities both within and beyond the veterinary environment will help convince educators, researchers and 
practitioners that this species-spanning approach is worthwhile and offers opportunities for career development, personal fulfillment and improved service delivery.

Veterinary social work blends the human side of veterinary medicine with the animal side of social work. As awareness of and interest in veterinary social work continues to grow, additional opportunities will emerge whereby social workers with an abiding interest in animals as well as people can help their clients, society, and the non-human members of families and communities.

\section{Compliance with Ethical Standards}

Conflict of interest The author declares that he has no conflict of interest to disclose.

\section{References}

Allison, M., Satterwhite, C., Ramaswamy, M., Hynek, M. T., \& Agnew-Svoboda, Z. (2017). Strategies veterinary practices can use to address the problem of intimate partner violence. Journal of the American Veterinary Medical Association, 250(1), 42-45.

American Veterinary Medical Association. (2007). U.S. pet ownership \& demographics sourcebook. Washington: American Veterinary Medical Association.

American Veterinary Medical Association. (2018). AVMA pet ownership and demographics sourcebook (2017-2018 ed.). Washington: American Veterinary Medical Association.

Anderson, L., Snow, D. A., \& Cress, D. (1994). Negotiating the public realm: Stigma management and collective action among the homeless. Research in Community Sociology, 1, 121-143.

Animal Welfare Foundation and The Links Group. (2016). Recognising abuse in animals and humans: Guidance for the veterinary team. London: British Veterinary Association.

Arkow, P. (2010). How did we come to be known as "humane societies", and what's our connection with the coast guard and the fire department? Latham Letter, 31(2), 6-16.

Arkow, P. (2013). The impact of companion animals on social capital and community violence: Setting research, policy and program agendas. Journal of Sociology \& Social Welfare, 40(4), 33-56.

Arkow, P. (2015a). A link across the lifespan: Animal abuse as a marker for traumatic experiences in child abuse, domestic violence and elder abuse. Shakopee, MN: Academy on Violence and Abuse.

Arkow, P. (2015b). Animal-assisted therapy \& activities: A study and research resource guide for the use of companion animals in animal-assisted interventions (11th ed.). Stratford, NJ: Author.

Arkow, P. (2019a). The social capital of companion animals: Pets as a catalyst for social networks and support... and a barometer of community violence. In A. H. Fine (Ed.), Handbook on animalassisted therapy: Foundations and guidelines for animal-assisted interventions (5th ed., pp. 51-60). Boca Raton: Academic Press.

Arkow, P. (2019b). Breaking the cycles of violence: A guide to multidisciplinary responses for domestic violence, child protection, adult protection, and animal care \& control agencies (3rd ed.). Alameda: Latham Foundation.

Arnott, S. (2004). Sleeping ruff: Edinburgh street dogs and their people [Video]. Vimeo. https://vimeo.com/6621701.
Ascione, F. R. (1998). Battered women's reports of their partners' and their children's cruelty to animals. Journal of Emotional Abuse, $1,119-133$

Ascione, F.R. (2000). Safe havens for pets: Guidelines for programs sheltering pets for women who are battered. Utah State University. https://www.vachss.com/guest_dispatches/safe_havens.html.

Ascione, F. R. (2007). Emerging research on animal abuse as a risk factor for intimate partner violence. In K. Kendall-Tackett \& S. Giacomoni (Eds.), Intimate partner violence (pp. 3-1-3-17). Princeton: Civic Research Institute.

Ascione, F. R., \& Arkow, P. (Eds.). (1999). Child abuse, animal abuse and domestic violence: Linking the circles of compassion for prevention and intervention. West Lafayette: Purdue University Press.

Ascione, F. R., Weber, C. V., \& Wood, D. S. (1997). The abuse of animals and domestic violence: A national survey of shelters for women who are battered. Society \& Animals, 5(3), 205-218.

Baker, A., \& Stelloh, T. (2011). Boy, 4, is mauled to death by dog in Brooklyn home (p. 22). New York: New York Times.

Baldry, A. C. (2005). Animal abuse among preadolescents directly and indirectly victimized at school and at home. Criminal Behaviour \& Mental Health, 15(2), 97-110.

Barnard-Nguyen, S., Breit, M., Anderson, K. A., \& Nielsen, J. (2016). Pet loss and grief: Identifying at-risk pet owners during the euthanasia process. Anthrozoös, 29(3), 421-430.

Becker, F., \& French, L. (2004). Making the links: Child abuse, animal cruelty, and domestic violence. Child Abuse Review, 13(6), $399-414$

Belluck, P. (2006, April 01). New Maine law shields animals in domestic violence cases. New York Times.https://www.nytim es.com/2006/04/01/us/new-maine-law-shields-animals-in-domes tic-violence-cases.html.

Boat, B. W. (2010). Understanding the role of animals in the family: Insights and strategies for clinicians. In A. H. Fine (Ed.), Handbook on animal-assisted therapy: Foundations and guidelines for animal-assisted interventions (3rd ed., pp. 265-282). Boca Raton: Academic Press.

Boat, B. W., \& Knight, J. C. (2000). Experiences and needs of Adult Protective Services case managers when assisting clients who have companion animals. Journal of Elder Abuse \& Neglect, 12(3/4), 145-155.

Bruni, F. (2019, Aug. 31). Dogs will fix our broken democracy. New York Times.https://www.nytimes.com/2019/08/31/opinion/dogsdemocracy.html.

Campbell, A.M. (2019, Spring). Following the links: The critical role of animal control in improving detection and prevention of family violence. Animal Care \& Control Today, 14-16.

Campbell, A. M., Hicks, R. A., Thompson, S. L., \& Wiehe, S. E. (2017). Characteristics of intimate partner violence incidents and the environments in which they occur: Victim reports to responding law enforcement officers. Journal of Interpersonal Violence, 32, 1-24. https://doi.org/10.1177/0886260517704230.

Campbell, A. M., Thompson, S. L., Harris, T. L., \& Wiehe, S. E. (2018). Intimate partner violence and pet abuse: Responding law enforcement officers' observations and victim reports from the scene. Journal of Interpersonal Violence, 33, 1-20. https://doi. org/10.1177/0886260518759653.

Canadian Centre for Child Protection. (2018). "Bestiality" as reflected in Canadian case law. Winnipeg: Author.

Carmack, B. J. (2003). Grieving the death of a pet. Minneapolis: Augsburg Fortress.

Chandler, C. K. (2005). Animal assisted therapy in counseling. London: Routledge.

Courthouse Dogs Foundation. (2015). Facility dogs at children's advocacy centers and in legal proceedings: Best practices. Bellevue, WA: Author. 
Courthouse Dogs Foundation. (2020a). Courthouse facility dogs in the U.S. Retrieved from https://courthousedogs.org/dogs/where /where-united-states/.

Courthouse Dogs Foundation (2020b). Appellate case law. Retrieved from https://courthousedogs.org/legal/appellate-case-law/.

Courthouse Dogs Foundation (2020c). CASA/GAL programs Retrieved from https://courthousedogs.org/dogs/dogs-at-work/ casa-programs/.

Currie, C. L. (2006). Animal cruelty by children exposed to domestic violence. Child Abuse \& Neglect, 30(4), 425-435.

Dunn, K., Mehler, S., \& Greenberg, H. (2005). Social work with a pet loss support group in a university veterinary hospital. Social Work in Health Care, 41(2), 59-70.

Edwards, M. J. (2019). Arrest and prosecution of animal sex abuse (bestiality) offenders in the United States, 1975-2015. Journal of the American Academy of Psychiatry and the Law, 47(3), 335-346.

Fawcett, N. R., \& Gullone, E. (2001). Cute and cuddly and a whole lot more? A call for empirical investigation into the therapeutic benefits of human-animal interaction for children. Behaviour Change, 18(2), 124-133.

Febres, J., Brasfield, H., Shorey, R. C., Elmquist, J., Ninnemann, A., ... Stuart, G. L. (2014). Adulthood animal abuse among men arrested for domestic violence. Violence Against Women, 20(9), 1059-1077.

Friedmann, E. (2019). The animal-human bond: Health and wellness. In A. H. Fine (Ed.), Handbook on animal-assisted therapy: Foundations and guidelines for animal-assisted interventions (5th ed., pp. 79-97). Boca Raton: Academic Press.

Garrity, T., \& Stallones, L. (1998). Effects of pet contact on human well-being. In C. C. Wilson \& D. C. Turner (Eds.), Companion animals in human health (pp. 3-22). London: Sage Publications.

Gullone, E. (2012). Animal cruelty, antisocial behaviour, and aggression: More than a link. London: Palgrave Macmillan.

Gullone, E., \& Robertson, N. (2008). The relationship between bullying and animal abuse in adolescents: The importance of witnessing animal abuse. Journal of Applied Developmental Psychology, 29(5), 371-379.

Henry, B. C., \& Sanders, C. E. (2007). Bullying and animal abuse: Is there a connection? Society \& Animals, 15(2), 107-126.

Hodgson, K., \& Darling, M. (2011). Pets in the family: Practical approaches. Journal of the American Animal Hospital Association, 47, 299-305.

Hoffer, T., Hargreaves-Cormany, H., Muirhead, Y., \& Meloy, J. R. (2018). Violence in animal cruelty offenders. New York: Springer Briefs in Psychology/Behavioral Criminology.

Hoy-Gerlach, J., Delgado, M., Sloane, H., \& Arkow, P. (2019). Rediscovering connections between animal welfare and human welfare: Creating social work internships at a humane society. Journal of Social Work, 19(2), 216-232.

Humane Society of the U.S. (2005). Helping vulnerable adults and their pets. Washington, DC: Author.

Irvine, L., Kahl, K. N., \& Smith, J. M. (2012). Confrontations and donations: Encounters between homeless pet owners and the public. The Sociological Quarterly, 53, 25-43.

Jalongo, M. R. (2004). The world's children and their companion animals: Developmental and educational significance of the child/ pet bond. Washington: Association for Childhood Education International.

Jury, A., Thorburn, N., \& Burry, K. (2018). Pet abuse as part of intimate partner violence. Wellington, NZ: National Collective of Independent Women's Refuges.

Kelly, G. (2017, May 7). Veterinary medicine is a woman's world. Veterinarian's Money Digest.https://www.vmdtoday.com/news/ veterinary-medicine-is-a-womans-world.
LaBahn, D. (2015). Providing comfort, companionship, and relief: The use of courtroom dogs. Lex Canis, 15, 4-10.

Labrecque, J., \& Walsh, C. (2011). Homeless women's voices on incorporating companion animals into shelter services. Anthrozoös, 24(1), 75-95.

Ladny, R. Y., \& Meyer, L. (2019). Traumatized witnesses: Review of childhood exposure to animal cruelty. Journal of Child \& Adolescent Trauma. https://doi.org/10.1007/s40653-019-00277-x.

Laing, M., \& Maylea, C. (2018). "They burn brightly, but only for a short time": The role of social workers in companion animal grief and loss. Anthrozoös, 31(2), 221-232.

Lange, A. M., Cox, J. A., Bernert, D. J., \& Jenkins, C. D. (2006). Is counseling going to the dogs? An exploratory study related to the inclusion of an animal in group counseling with adolescents. Journal of Creativity in Mental Health, 2(2), 17-31.

Larkin, M. (2016). For human needs, some veterinary clinics are turning to a professional: Social workers see a place for themselves in veterinary practice. Journal of the American Veterinary Medical Association, 248(1), 8-12.

Larkin, M. (2018). When domestic violence arrives at the clinic door: How veterinary staff can respond to abused clients and patients. Journal of the American Veterinary Medical Association, 253(6), $656-660$.

Levinthal, J. (2010). The community context of animal and human maltreatment: Is there a relationship between animal maltreatment and human maltreatment: Does neighborhood context matter? (Doctoral dissertation, University of Pennsylvania). https://repos itory.upenn.edu/edissertations/274.

Lockwood, R. (2002). Making the connection between animal cruelty and abuse and neglect of vulnerable adults. Latham Letter, 23(1), $10-11$.

Long, D. D., \& Kulkarni, S. J. (2013). Cross-reporting of interpersonal violence and animal cruelty: The Charlotte Project. Journal of Sociology and Social Welfare, 40(4), 131-148.

McNicholas, J., \& Collis, G. (2006). Animals as social supports: Insights for understanding animal-assisted therapy. In A. H. Fine (Ed.), Handbook on animal-assisted therapy: Foundations and guidelines for animal-assisted interventions (2nd ed., pp. 49-72). Boca Raton: Academic Press.

McIntosh, S. (2002). The links between animal abuse and family violence, as reported by women entering shelters in Calgary communities. Cremona, AB: Author.

Mead, M. (1964). Cultural factors in the cause and prevention of pathological homicide. Bulletin of the Menninger Clinic, 28, 11-22.

Melson, G. F. (2001). Why the wild things are: Animals in the lives of children. Cambridge: Harvard University Press.

Melson, G. F. (2013). Children's ideas about the moral standing and social welfare of non-human species. Journal of Sociology \& Social Welfare, 40(4), 81-106.

Melson, G. F., \& Fine, A. H. (2006). Animals in the lives of children. In A. H. Fine (Ed.), Handbook on animal-assisted therapy: Foundations and guidelines for animal-assisted interventions (2nd ed., pp. 207-226). Boca Raton: Academic Press.

Melson, G. F., \& Fine, A. H. (2015). Animals in the lives of children. In A. H. Fine (Ed.), Handbook on animal-assisted therapy: Foundations and guidelines for animal-assisted interventions (4th ed., pp. 179-194). Boca Raton: Academic Press.

Menzies, I. (2003). Animal assisted therapy and young people: A review of selected literature. Melbourne: Author.

Messent, P. (1983). Social facilitation of contact with other people by pet dogs. In A. H. Katcher \& A. M. Beck (Eds.), New perspectives on our lives with companion animals (pp. 37-46). Philadelphia: University of Pennsylvania Press.

Miller, T. A. K., Prout, M. F., Rourke, M., Lefkowitz, C., \& Boyer, B. (2014). A therapist's guide to treating grief after the loss of 
a pet: A three-tier model. Human-Animal Interaction Bulletin, 2(1), 38-58.

Nathanson, J. N. (2009). Animal hoarding: Slipping into the darkness of comorbid animal and self-neglect. Journal of Elder Abuse \& Neglect, 21(4), 307-324.

National Link Coalition (2014). Safety planning for pets.https://natio nallinkcoalition.org/wp-content/uploads/2013/01/DV-SafetyPlan ningCompilation.pdf.

National Link Coalition. (2015). “Three-dimensional” New Zealand veterinarians respond to domestic violence. LINK-Letter, 8(10), 5.

National Link Coalition. (2017). The "power and control wheel" of animal abuse and domestic violence. Etowah, NC: Author.

National Link Coalition. (2019a). Social work and the violence link. LINK-Letter, 12(12), 14-15.

National Link Coalition. (2019b). The connection between animal cruelty and societal violence and vulnerability. LINK-Letter, 12(12), 9-10.

National Link Coalition. (2019c). Pets in protection orders by state. https://nationallinkcoalition.org/wp-content/uploads/2020/06/ PPO-Summary-by-State-2020-6.pdf.

National Link Coalition. (2019d). Four funding opportunities announced to support co-sheltering. LINK-Letter, 12(3), 1-3.

National Link Coalition. (2020). Schools of social work with humananimal interactions in curriculum. Etowah, NC: Author.

Netting, F. E., Wilson, C. C., \& New, J. C. (1987). The human-animal bond: Implications for practice. Social Work, 32(1), 60-64.

Newland, X., Boller, M., \& Boller, E. (2019). Considering the relationship between domestic violence and pet abuse and its significance in the veterinary clinical and educational contexts. New Zealand Veterinary Journal, 67(2), 55-65.

O'Reilly-Jones, K. (2019). When Fido is family: How landlordimposed pet bans restrict access to housing. Columbia Journal of Law \& Social Problems, 52(3), 427-472.

Parkes, D., \& Signal, T. (2017). Revisiting a link: Animal abuse, bullying, and empathy in Australian youth. Human-animal Interaction Bulletin, 5(1), 26-40.

Paterson, K. (2015, Sept. 15). Vets enlisted in bid to stop domestic abuse. The National.https://www.thenational.scot/news/14899 535.vets-enlisted-in-bid-to-stop-domestic-abuse/.

Patronek, G. J., Loar, L., \& Nathanson, J. N. (Eds.). (2006). Animal hoarding: Structuring interdisciplinary responses to help people, animals and communities at risk. North Grafton, MA: Hoarding of Animals Research Consortium.

Patronek, G. J., \& Nathanson, J. N. (2009). A theoretical perspective to inform assessment and treatment strategies for animal hoarders. Clinical Psychology Review, 29, 274-281.

Peak, T., Ascione, F. R., \& Doney, J. (2012). Adult protective services and animal welfare: Should animal abuse and neglect be assessed during adult protective services screening? Journal of Elder Abuse \& Neglect, 24(1), 37-49.

PetLynx. (2011). 2010 national urban animal report. Edmonton, AB: Author.

Phillips, A. (2019). Start-up manual (3rd ed.). Lansing, MI: Sheltering Animals and Families Together (SAF-T).

Putnam, R. (2000). Bowling alone: The collapse and revival of American community. Cambridge: Harvard University Press.

Quackenbush, J. (1984). Pet bereavement in older owners. In R. K. Anderson, B. L. Hart, \& L. A. Hart (Eds.), The pet connection: Its influence on our health and quality of life (pp. 292-299). Minneapolis: University of Minnesota.

Quackenbush, J. E. (1981). Pets, owners, problems, and the veterinarian: Applied social work in a veterinary teaching hospital. The Compendium on Continuing Education for the Small Animal Practitioner, 3(9), 764-770.
Quackenbush, J., \& Glickman, L. (1983). Social work services for bereaved pet owners: A retrospective case study in a veterinary teaching hospital. In A. H. Katcher \& A. M. Beck (Eds.), New perspectives on our lives with companion animals (pp. 377-389). Philadelphia: University of Pennsylvania Press.

Quinlisk, A. (1999). Animal abuse and family violence. In F. R. Ascione \& P. Arkow (Eds.), Child abuse, domestic violence, and animal abuse: Linking the circles of compassion for prevention and intervention (pp. 168-175). West Lafayette: Purdue University Press.

Reichert, E. (1998). Individual counseling for sexually abused children: A role for animals and storytelling. Child and Adolescent Social Work Journal, 15(3), 177-185.

Rémillard, L. W., Meehan, M. P., Kelton, D. F., \& Coe, J. B. (2017). Exploring the grief experience among callers to a pet loss support hotline. Anthrozoös, 30(1), 149-161.

Risley-Curtiss, C. (2010). Social work practitioners and the human companion animal bond: A national study. Social Work, 55(1), $38-46$.

Risley-Curtiss, C. (2013). Expanding the ecological lens in child welfare practice to include other animals. Journal of Sociology \& Social Welfare, 40(4), 107-130.

Risley-Curtiss, C., Holley, L. C., Cruickshank, T., Porcelli, J., Rhoads, C., Bacchus, D., ... Murphy, S. B. (2006a). "She was family:" Women of color and their animal human connections. Affilia, 21, 433-447.

Risley-Curtiss, C., Holley, L. C., \& Wolf, S. (2006b). The animalhuman bond and ethnic diversity. Social Work, 51(3), 257-268.

Robbins, S. (2018, May 28). Florida woman held captive by boyfriend slips note to vet staff: "Call the cops." Daytona Beach NewsJournal. Retrieved from https://www.news-journalonline.com/ zz/news/20180528/florida-woman-held-captive-by-boyfriendslips-note-to-vet-staff-call-cops.

Roguski, M. (2012). Pets as pawns: The co-existence of animal cruelty and family violence. Auckland, NZ: Royal New Zealand Society for the Prevention of Cruelty to Animals.

Ross, C. (2005). Pet loss and children: Establishing a healthy foundation. London: Routledge.

Royal College of Veterinary Surgeons. (2016). Code of professional conduct for veterinary surgeons, Supporting guidance No. 14 (client confidentiality). London: Royal College of Veterinary Surgeons.

Sanders, C. E., \& Henry, B. C. (2015). Nonhuman animal cruelty, bullying, and behavioral difficulties among women. Society \& Animals, 23(1), 68-80.

Saskatchewan Society for the Prevention of Cruelty to Animals and Saskatchewan Towards Offering Partnership Solutions (STOPS) to Violence. (2016). The link: Interpersonal violence and abuse and animal safekeeping. Saskatoon, SK: Authors.

Sato, A. (2011). Social workers' attachments to their pets, organizational structures, and their impact on professional assessment regarding the roles pets play in clients' lives (Doctoral Dissertation). Retrieved from https://opencommons.uconn.edu/dissertati ons/AAI3504777.

Schneider, M., \& Roberts, J. (2016). Shelter-specific occupational stress among employees in animal shelters. Human-Animal Interaction Bulletin, 4(1), 19-38.

Silverman, Y. (2018). The role of animals as therapeutic aids in private practice. Washington, DC: National Association of Social Workers Practice Perspectives.

Strand, E. B., \& Faver, C. A. (2005). Battered women's concern for their pets: A closer look. Journal of Family Social Work, 9(4), $39-58$.

Turner, W. G. (2006). The role of companion animals throughout the family life cycle. Journal of Family Social Work, 9(4), 11-21. 
Vaughn, M. G., Fu, Q., Beaver, K. M., DeLisi, M., Perron, B. E., \& Howard, M. O. (2011). Effects of childhood adversity on bullying and cruelty to animals in the United States: Findings from a national sample. Journal of Interpersonal Violence, 26(17), 3509-3525.

Veterinary Council of New Zealand. (2013). Guidance for veterinarians dealing with cases of suspected or actual animal Abuse and family violence. Wellington, NZ: Author.

Vincent, A., McDonald, S., Poe, B., \& Deisner, V. (2019). The Link between interpersonal violence and animal abuse. Society Register, 3(3), 83-101.

Walker, J. R. (1980). A study on the relationship of child abuse and pet abuse. [Unpublished professional project]. University of Pennsylvania School of Social Work.

Walters, G. D. (2019). Animal cruelty and bullying: Behavioral markers of delinquency risk or causal antecedents of delinquent behavior? International Journal of Law and Psychiatry, 62, 77-84.

Walton-Moss, B. J., Manganello, J., Frye, U., \& Campbell, J. C. (2005). Risk factors for interpersonal violence and associated injury among urban women. Journal of Community Health, 30(5), 377-389.

Williams, D. L., \& Hogg, S. (2016). The health and welfare of dogs belonging to homeless people. Pet Behaviour Science, 1, 23-30.
Wood, L. (2009). Living well together: How companion animals can help strengthen social fabric. Perth, WA: Petcare Information \& Advisory Service and the Centre for the Built Environment and Health (School of Population Health), University of Western Australia.

Wood, L., Giles-Corti, B., \& Bulsara, M. K. (2005). The pet connection: Pets as a conduit for social capital? Social Science \& Medicine, 61, 1159-1173.

Wood, L., Giles-Corti, B., Bulsara, M. K., \& Bosch, D. A. (2007). More than a furry companion: The ripple effect of companion animals on neighborhood interactions and sense of community. Society and Animals, 15(1), 43-56.

Wood, L., Martin, K., Christian, H., Houghton, S., Kawachi, I., Vallesi, S., ... McCune, S. (2017). Social capital and pet ownership-A tale of four cities. SSM Population Health, 3, 442-447.

Zilney, L. A., \& Zilney, M. (2005). Reunification of child and animal welfare agencies: Cross-reporting of abuse in Wellington County, Ontario. Child Welfare, 84(1), 47-66.

Publisher's Note Springer Nature remains neutral with regard to jurisdictional claims in published maps and institutional affiliations. 